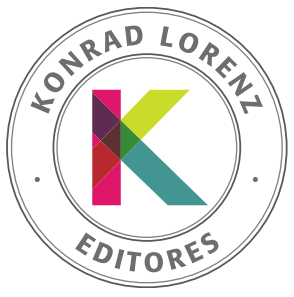

http://sumapsicologica.konradlorenz.edu.co

\title{
Cross-cultural measurement invariance in the Satisfaction with Life Scale in Chilean and Spanish university students
}

\author{
Berta Schnettler a,f,*, Edgardo Miranda-Zapata b, Mercedes Sánchez c, Ligia Orellana f, \\ Germán Lobos ${ }^{d}$, Cristian Adasme-Berríos $^{e}$, José Sepúlveda ${ }^{f}$, Clementina Hueche ${ }^{f}$
}

a Departamento de Producción Agropecuaria, Universidad de La Frontera, Chile

${ }^{b}$ LICSA, Núcleo Científico y Tecnológico en Ciencias Sociales, Universidad de La Frontera, Temuco, Chile

c Departamento de Gestión de Empresas, Universidad Pública de Navarra, España

${ }^{d}$ Facultad de Economía y Negocios, Universidad de Talca, Chile

e Departamento de Economía y Administración, Universidad Católica del Maule, Talca, Chile

${ }^{f}$ Centro de Excelencia en Psicología Económica y del Consumo, Núcleo Científico y Tecnológico en Ciencias Sociales, Universidad de La Frontera, Chile

Received 6 May 2021; accepted 4 August 2021

\section{KEYWORDS}

Satisfaction with life, measurement invariance, culture, university students, subjective well-being

\begin{abstract}
Introduction: The Satisfaction with Life Scale (SWLS) is a widely used measure of an individuals' cognitive assessment of subjective well-being. The SWLS has been validated in several contexts and populations, but its cross-cultural measurement invariance in emerging adult samples remains barely explored. The purpose of this study was to evaluate the measurement invariance of the SWLS in university students from Chile and Spain and according to gender. Method: A non-probabilistic sample of 165 university students from Chile $(66.7 \%$ women, $\left.M_{\text {age }}=21.9, S D=2.35\right)$, and 109 students from Spain $\left(48.6 \%\right.$ women; $\left.M_{\text {age }}=22.9, S D=2.4\right)$ completed the SWLS. Results: Using multi-group confirmatory factor analysis, results showed that the SWLS exhibited configural, metric and scalar invariance in the comparison between the Chilean and Spanish student samples and also according to gender. Conclusions: This finding allows for significant latent mean comparisons between cross-cultural samples. Moreover, this study supports the SWLS as a valid instrument which provides data that can inform policies in order to improve the subjective well-being of university students of both genders, both in developed and developing Spanish-speaking countries.

(c) 2021 Fundación Universitaria Konrad Lorenz. This is an open access article under the CC BY-NC-ND license (http://creativecommons.org/licenses/by-nc-nd/4.0/).
\end{abstract}

\footnotetext{
* Corresponding author.
}

E-mail: berta.schnettler@ufrontera.cl 


\section{PALABRAS CLAVE:}

Satisfacción con la vida, invarianza de medida, cultura, estudiantes universitarios, bienestar subjetivo

\section{Invarianza de medida transcultural en la Escala de Satisfacción con la Vida en estudiantes} universitarios de Chile y España

Resumen Introducción: La Escala de Satisfacción con la Vida (SWLS) es un instrumento ampliamente utilizado para la evaluación cognitiva del bienestar subjetivo de los individuos. La SWLS ha sido validada en numerosos contextos y poblaciones, pero la invarianza de medida a nivel transcultural en adultos emergentes ha sido poco explorada. El propósito de este artículo fue evaluar la invarianza de medida de la SWLS en estudiantes universitarios de Chile y España y según género. Método: Una muestra no probabilística de 165 estudiantes universitarios de Chile $(66.7 \%$ mujeres, edad promedio $=21.9, D E=2.35)$ y 109 estudiantes de España $(48.6 \%$ mujeres, edad promedio $=22.9, D E=2.4$ ) completaron la SWLS. Resultados: Por medio de un análisis factorial confirmatorio multigrupo, los resultados mostraron que la SWLS exhibió invarianza configural, métrica y escalar en la comparación entre las muestras de estudiantes chilenos y españoles y según género. Conclusión: Este hallazgo muestra que la SWLS permite comparaciones significativas de medias latentes entre muestras transculturales universitarias. Además, este estudio aporta evidencia de la SWLS como un instrumento válido que puede guiar la creación de políticas para mejorar el bienestar subjetivo de los estudiantes universitarios de ambos géneros, tanto en países desarrollados como en desarrollo de habla hispana.

(C) 2021 Fundación Universitaria Konrad Lorenz. Este es un artículo Open Access bajo la licencia CC BY-NC-ND (http://creativecommons.org/licenses/by-nc-nd/4.0/).
Subjective well-being (SWB, Diener \& Biswas-Diener, 2000 ) is a person's assessment of their own life, which involves an emotional component, encompassed by the construct of happiness (Arita, 2005), and a cognitive component, satisfaction with life (Diener et al., 1985). Different cultures hold different meanings regarding what encompasses well-being and a good life. The Satisfaction with Life Scale (SWLS; Diener et al., 1985) is one of the most widely used scales to globally measure the cognitive component of SWB (Atienza et al., 2016; Dimitrova \& Dominguez, 2015; Oishi, 2006; Sovet et al., 2016; Tomás et al., 2015; Whisman \& Judd, 2016). Given its extensive use across different cultures and populations, researchers using the SWLS need to ensure that the psychometric equivalence of this construct holds up across groups or across time (Huang et al., 2011). The assessment of this equivalence is termed measurement invariance, a key analysis in both psychological and developmental research because it is a prerequisite for comparing group means (Huang et al., 2011; Jang et al., 2017; Putnick \& Bornstein, 2016). Cultural differences in interpreting satisfaction with life can result in nonequivalence of measures, or measurement noninvariance (Jang et al., 2017).

Research shows that individuals typically compare their actual life circumstances with their ideal life circumstances when evaluating satisfaction with life (Zanon et al., 2014). These "ideal life circumstances" and perceptions of well-being may differ among nations due to country characteristics, political climates, and societal values (Ponizovsky et al., 2013). Diener et al. (2013), and Jang et al. (2017) suggesting that there are cultural differences in values and practices which affect how people understand and report life satisfaction, as well as the weight they give to different variables that influence life satisfaction judgments. These judgments may differ based on whether individuals belong to individualistic or collectivistic cultures, religious or non-religious societies, or in developed or developing countries (Diener et al., 2013). Judgements may also differ among members in the same overall cultural context but with multilanguage acculturation (Salazar-Fernández et al., 2020).
Researchers have broached the cultural sensibility of the SWLS (Atienza et al., 2016; Schnettler et al., 2017), although results have been inconclusive. Differences in the SWLS scores among countries may be ascribed to a measurement error due to cultural differences in interpreting the given scale items (Zanon et al., 2014), plus the same mean scores from different countries may not reflect the same actual levels of satisfaction with life (Jang et al., 2017). Tucker et al. (2006) reported metric invariance when comparing US and Russian university student and community samples, and lack of invariance when only community samples were included. Swami and ChamorroPremuzic (2009) reported that the SWLS remained invariant across genders and ethnic groups when comparing samples of Malay and Chinese adults from Malaysia. Dimitrova and Dominguez (2015) found partial scalar invariance (i.e., the intercept of each item for all groups) in emerging adults and adults from Argentina, Mexico, and Nicaragua. Casas et al. (2012) found metric invariance in four out of the five scale items among adolescent samples from Brazil, Chile, and Spain. Ponizovsky et al. (2013) demonstrated SWLS measurement invariance among immigrants of various age groups. Díaz et al. (2015) found that the SWLS and the Psychological Well-being Scales load on the same factor, showing an excellent data fit, with factor loadings and error variance being equivalent among adult samples from Spain and Colombia. Whisman and Judd (2016) confirmed partial scalar invariance using a sample of 50-to-79-year-old adults in the US, England, and Japan, as did Atienza et al. (2016) in a sample of Spanish and Portuguese adolescents. Esnaola et al. (2017) found strict invariance (i.e., residual invariance for each item is the same throughout groups) regarding country and gender, and scalar invariance for age, in a sample of Mexican and Spanish adolescents. Schnettler et al. (2017) reported partial measurement invariance among Chilean and Ecuadorian older adult samples. In Chile, Salazar-Fernández et al. (2020) reported strict invariance between acculturated and bicultural, and between acculturated men and women 
from the Mapuche indigenous group. Lastly, Jang et al. (2017) conducted a measurement invariance study in 26 countries finding that configural (i.e., items load onto the same latent factor throughout groups) and metric (i.e., factor loading of each item onto latent factor is the same for all groups) invariances held for all countries, but scalar invariance (i.e., intercept of each item is the same among groups) did not.

Differences in how individuals interpret and conceptualise the SWLS items may contribute to the failure to meet the criteria for different invariance levels (Oishi, 2006; Tucker et al., 2006, Zanon et al., 2014). This occurrence may be due to cultural differences (Atienza et al., 2016; Oishi, 2006, Salazar-Fernández et al., 2020; Schnettler et al., 2017; Zanon et al., 2014) or age (Casas et al., 2012; Esnaola et al., 2017; Tucker et al., 2006, Whisman \& Judd, 2016, Wu et al., 2009). Jang et al. (2017) have shown that a dissimilar mean age throughout countries significantly affected the intercept of Item 4, which states "So far I have gotten the important things I want in life". The literature indicates that this item is endorsed more by elder than by younger respondents, thus elder samples may have a significantly higher intercept than younger samples. This suggestion is consistent with cross-sectional and longitudinal studies which point out that satisfaction with life is age-sensitive (Clench-Aas et al., 2011; Wu et al., 2009).

To the best of our knowledge, only three studies have assessed the cross-cultural invariance of the scale exclusively using university student samples. Assessing satisfaction with life in these samples is attracting more interest in the literature, however (Tsitsas et al., 2019) this interest entails attending the specific life conditions of emerging adults who are attending school, as they often face stress personally (Cadime et al., 2016), socially, academically, economically, and in other areas of life (Çivitci, 2015; Hiçdurmaz et al., 2017; Lee et al., 2017), regardless of the country or culture in which they live. Studies conducted with university student samples so far have included the measurement invariance of the SWLS across gender (Hultell \& Gustavsson, 2008; Shevlin et al., 1998; Sovet et al., 2016; Tomás et al., 2015), age (Hultell \& Gustavsson, 2008; Tomás et al., 2015), and time (Wu et al., 2009). However, cross-cultural invariance for the SWLS in these populations has been less thoroughly explored.

Moreover, as with the findings in the samples of adolescents, adults and older adults, the findings with university student samples are inconclusive. Whereas Tucker et al. (2006) reported strict invariance when comparing US and Russian student samples, Oishi (2006) found that item 5 was not invariant among Chinese and US university students. Similarly, Zanon et al. (2014) found that items 4 and 5 were noninvariant among Brazilian and US university student samples. Therefore, further research is required to analyse the cross-cultural equivalence of the SWLS among university students from different countries and cultures. Cross-cultural equivalence among university students is especially relevant given student mobility between countries and continents for university studies. A measure that consistently captures the construct of satisfaction with life throughout cultures can aid in the development of institutional interventions and policies that improve the well-being of students from diverse backgrounds.
Therefore, the present study examines the measurement invariance of the SWLS among university student samples from Chile and Spain using multi-group confirmatory factor analysis. Although both Spanish-speaking countries share cultural characteristics due to their historical relationship (i.e., Chile was a Spanish colony until the early 1800 s), each of these nations possesses significant cultural distinctions (Arenas-Gaitán et al., 2011). For example, Hofstede and Bond (1988) identified differences in the cultural dimension of individualism vs collectivism in Chilean and Spanish citizens. Likewise, Arenas-Gaitán et al. (2011) found significant differences in the dimensions of power distance and masculinity vs. femininity among Chilean and Spanish undergraduate students. In Jang et al.'s (2017) cross-cultural study of the SWLS invariance, Chile was shown to have the highest factor mean of life satisfaction, whereas Spain presented the lowest. Taken together, these findings indicate the need for further exploration of the cross-cultural equivalence of satisfaction with life in young adults in Chile and Spain. Therefore, the purpose of this study was to evaluate the measurement invariance of the SWLS in university students in Chile and Spain. As research indicates that life satisfaction differs by gender in university students (Tomás et al., 2015), the measurement invariance by gender was also assessed regardless of the country of origin.

\section{Method}

\section{Participants}

This study used two non-probabilistic samples of undergraduate students, one from Chile and one from Spain. In Chile, 165 university students were recruited from five state universities nationwide $(66.7 \%$ women, mean age $=21.9$, $S D=2.35$ ), and participants responded to an online questionnaire. In Spain, 109 students from one state university $(48.6 \%$ women; mean age $=22.9, S D=2.4)$ in Pamplona responded to a printed questionnaire. All participants were of Chilean or Spanish nationality, respectively.

There was no missing data. In Spain, trained interviewers administered the questionnaire to ensure that all questions were answered. In Chile, all responses were mandatory in the online survey.

This study is part of a larger research project which examined variables related to life satisfaction in university students in Chile. This study was approved by the Bioethics Committee of the Universidad de La Frontera.

\section{Instrument}

The Satisfaction with Life Scale [SWLS] (Diener et al., 1985). This scale consists of five items grouped into a single dimension ("In most ways my life is close to my ideal"; "The conditions of my life are excellent"; "I am satisfied with my life"; "So far I have gotten the important things I want in life"; "If I could live my life over, I would change almost nothing"). A validated Spanish-language version of the SWLS scale was used in this study (Schnettler et al., 2013), which has shown good levels of internal consistency (Cronbach's $\alpha$ ranging from .87 to .88 ) in studies with university 
students and adults in Spain (Vázquez et al., 2013) and in Chile (Schnettler et al., 2014; Schnettler et al., 2015; Schnettler et al., 2016). The response format type was a 6-point Likert scale (1: strongly disagree to 6: strongly agree), as previous testing of the instruments suggested a tendency of respondents to concentrate answers at the midpoint (Schnettler et al., 2013). Thus, scores ranged from 5 to 30, and a higher score entailed greater life satisfaction.

\section{Procedure}

In the Chilean sample, data was collected online (QuestionPro, Inc) during September and November 2014. Potential participants received an invitation to participate in this study, which included a link to the front page of the survey with information regarding the aims of this study and the anonymous and confidential handling of the data. The informed consent form on the front page was available for participants to download as a PDF version. Students who agreed to participate in the study were requested to check the box at the bottom of the front page to proceed with the survey. In the Spanish sample, students were contacted on campus and a trained surveyor administered the questionnaires in person during September and October 2015.

Although the Chilean and Spanish participants were approached using different methods, Ponizovsky et al. (2013) has shown that data collected over the Internet can be comparable to data collected using in-person methods. Furthermore, it was ensured that the same information regarding the study aims, anonymity and confidentiality, and questionnaire structure was delivered to all participants in both samples by means of the informed consent.

\section{Data Analysis}

The Statistical Package for Social Sciences (IBM SPSS) v. 23 was employed for descriptive analysis. The Cronbach $\alpha$ coefficient was used to examine the reliability and internal consistency of the scale for each sample (> .7). Mplus v. 7.3 software was used to evaluate the one-dimensional factor structure of the SWLS in each subsample (Spanish, Chilean, male, and female; the latter two including participants from both countries) by means of confirmatory factor analysis (CFA), and to test the measurement invariance of the SWLS model between the Chilean and Spanish samples as well as between the male and female samples regardless of the country, using multi-group confirmatory factor analysis.
Considering the ordinal scale of the items, the polychoric correlation matrix was used to perform the CFA with Robust Unweighted Least Squares as the estimation method.

Different outcomes were considered for the analysis. To test the invariance of the factor model in the samples according to the country and gender, configural invariance, metric invariance and scalar invariance were verified (Dimitrov, 2010). To determine model fit of the data of the one-dimensional factor structure of the SWLS, and to determine the achievement of configural invariance, model Chi-square $\left(\alpha^{2}\right)$, Comparative Fit Index (CFI), Tucker-Lewis Index (TLI), and Root Mean Square Error of Approximation (RMSEA) were used. Criteria for good model fit were nonsignificant model Chi-square, CFI > 0.96, TLI >0.95, and RMSEA < 0.06 (Hu \& Bentler, 1999). Model fit was considered acceptable when CFI $>0.90$, TLI $>0.90$, and RMSEA $<0.08$ (Marsh et al., 2004). Lastly, to establish the achievement of metric and scalar invariance, a nonsignificant Delta of Satorra-Bentler Chi-square adjustment (D_SB $\chi^{2}$ ) was required (Satorra \& Bentler, 2001).

An independent sample t-test was applied to compare mean levels of the SWLS scores of university students from Chile and Spain and between genders, using the Statistical Package for Social Sciences (IBM SPSS) v. 23.

\section{Results}

The standardised factor loadings and descriptive statistics and goodness-of-fit indices of both the Chilean and Spanish samples are displayed on Table 1. The CFA from both countries showed fit indices which provide support for a one-dimensional factor structure and reliability. Although the $\chi^{2}$ test was significant, it is well established that the $\chi^{2}$ test is sensitive to sample size (MacCallum et al., 2006).

Table 2 shows the results and comparisons of model fits for cross-cultural measurement invariance of the SWLS. The $\chi^{2}$ test was also significant in Model 0 (MacCallum et al., 2006). Therefore, considering the fit indices, the overall fit of the baseline model was acceptable, which established the configural invariance of the SWLS in Chilean and Spanish university students. This finding supports the presence of a single-factor model in the two countries, and thus indicates that both university student groups conceptualise life satisfaction in the same one-dimensional structure. This model served as a basis for comparison for the metric measurement invariance model.

Consequently, factor loadings were constrained to be equal throughout groups to test for metric invariance (Table 2).

Table 1 Descriptive statistics of the Satisfaction with Life Scale scores in a sample of Chilean and Spanish university students

\begin{tabular}{|c|c|c|c|c|c|c|c|c|c|c|}
\hline \multirow{2}{*}{ Item } & \multicolumn{5}{|c|}{ Chilean $(n=165)^{a}$} & \multicolumn{5}{|c|}{ Spanish $(n=109)^{b}$} \\
\hline & Loadings & $M$ & $S D$ & Skewness & Kurtosis & Loadings & $M$ & $S D$ & Skewness & Kurtosis \\
\hline 1 & 0.896 & 4.13 & 1.17 & -0.75 & 0.03 & 0.872 & 3.79 & 1.27 & -0.56 & -0.67 \\
\hline 2 & 0.786 & 4.19 & 1.19 & -0.64 & -0.06 & 0.747 & 4.19 & 1.15 & -0.39 & 0.70 \\
\hline 3 & 0.901 & 4.44 & 1.22 & -0.75 & 0.06 & 0.878 & 4.38 & 1.30 & -0.84 & -0.11 \\
\hline 4 & 0.742 & 4.55 & 1.17 & -0.89 & 0.53 & 0.699 & 4.29 & 1.19 & -0.62 & -0.57 \\
\hline 5 & 0.585 & 4.10 & 1.50 & -0.46 & -0.76 & 0.537 & 3.78 & 1.58 & -0.11 & -1.12 \\
\hline
\end{tabular}

${ }^{\mathrm{a}} \chi^{2}(\mathrm{df})=477.6(10), p<.01, \mathrm{RMSEA}=.041, \mathrm{CFI}=.997, \mathrm{TLI}=.994$. Cronbach's $\alpha=.877$

${ }^{\mathrm{b}} \chi^{2}(\mathrm{df})=426.4(10), p<.01, \mathrm{RMSEA}=.027, \mathrm{CFI}=.999, \mathrm{TLI}=.998$. Cronbach's $\alpha=.808$ 
Table 2 Factorial Invariance for the Satisfaction with Life Scale model in a sample of Chilean and Spanish university students

\begin{tabular}{|c|c|c|c|c|c|c|c|c|}
\hline Model & $\chi^{2}$ & df & D_SB $\chi^{2}$ & D_df & P_D_SB $\chi^{2}$ & RMSEA & CFI & TLI \\
\hline 0 Configural (without invariance) & 25.509 & 14 & - & - & - & 0.077 & 0.991 & 0.988 \\
\hline 1 Metric (all loadings fixed) & 34.231 & 20 & 12.252 & 6 & 0.057 & 0.072 & 0.989 & 0.989 \\
\hline $\begin{array}{l}2 \text { Scalar (all loadings and thres- } \\
\text { holds fixed) }\end{array}$ & 43.207 & 33 & 11.482 & 13 & 0.511 & 0.048 & 0.992 & 0.995 \\
\hline
\end{tabular}

$\chi^{2}=$ Chi square. $\mathrm{df}=$ Degrees of freedom. D_SB $\chi^{2}=$ Delta of Satorra-Bentler adjustment of Chi-square. D_df = Delta of degrees of freedom. P_D_SB $\chi^{2}=$ Statistical significance of Delta of Satorra-Bentler adjustment of Chi-square. RMSEA = Root Mean Square Error of Approximations. $\mathrm{CFI}=$ Comparative Fit Index. TLI = Tuker-Lewis Index.

The SB $\chi^{2}$ difference test between configural invariance (Model 0 ) and metric invariance (Model 1) models was not significant, demonstrating support for metric invariance. Therefore, the factor loadings were invariant among university students from both countries. Thus, each item on the SWLS contributes in a similar degree to the latent variable among the university student samples from these two countries.

Next, equality of thresholds throughout groups was imposed on the model to test for scalar invariance (Table 2). The SB $\chi^{2}$ difference test between the metric invariance (Model 1) and scalar invariance (Model 2) models was not significant, demonstrating a scalar invariance. This finding indicates that group mean differences in the latent construct capture all of the mean differences in the shared variance of the items (Figures 1 and 2). Reaching a scalar invariance allows us to compare group means on the latent factor (Putnick \& Bornstein, 2016).

The CFA from both male $\left(\chi^{2}(\mathrm{df})=759.6(10), p<.01\right.$, RM$\mathrm{SEA}=.070, \mathrm{CFI}=.996, \mathrm{TLI}=.991)$ and female university students $\left(\chi^{2}(\mathrm{df})=978.4(10), p<.01\right.$, RMSEA = .046, CFI = .999, $\mathrm{TLI}=.997)$ also presented fit indices which provide support for a one-dimensional factor structure and reliability (male Cronbach's $\alpha=.826$, female Cronbach's $\alpha=.877$ ). The results of the multigroup analysis by gender are displayed on Table 3, showing that the model achieved configural, metric and scalar invariance (Figures 3 and 4.).

The Spanish (Mean $=20.4, S D=4.9)$ and the Chilean (Mean $=21.4, S D=5.1$ ) samples did not differ in the average scores for the SWLS $(t=1.588, p=.114)$. Likewise, the male $($ Mean $=20.9, S D=5.0)$ and the female $($ Mean $=21.1$, $S D=5.1)$ samples did not differ in the average scores for the $\operatorname{SWLS}(t=-.262, p=.794)$.

\section{Discussion}

This study examined the measurement invariance of the SWLS among university student samples from Chile and Spain using multi-group confirmatory factor analysis. Previous studies have assessed cross-cultural invariance in the SWLS in developing Spanish-speaking countries (Dimitrova \& Dominguez, 2015, Schnettler et al., 2017), by comparing developed and developing countries (Casas et al., 2012). This study expands on the evidence of cross-cultural invariance of the SWLS by examining this scale on university student samples from developed and developing Spanish-speaking countries. The results suggest configural, metric and scalar invariance of the SWLS among university students in Chile and Spain, indicating that the SWLS is a valid instrument for cross-cultural comparisons regarding undergraduate populations from these countries.

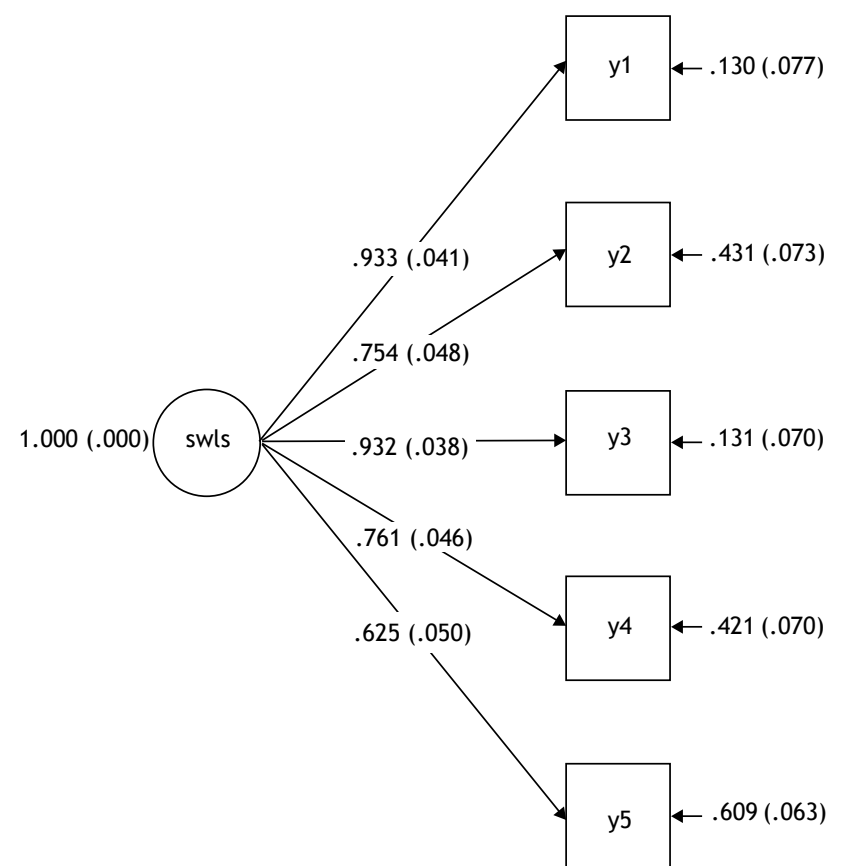

Figure 1. Path diagram of the Satisfaction with Life Scale for a sample of Chilean university students.

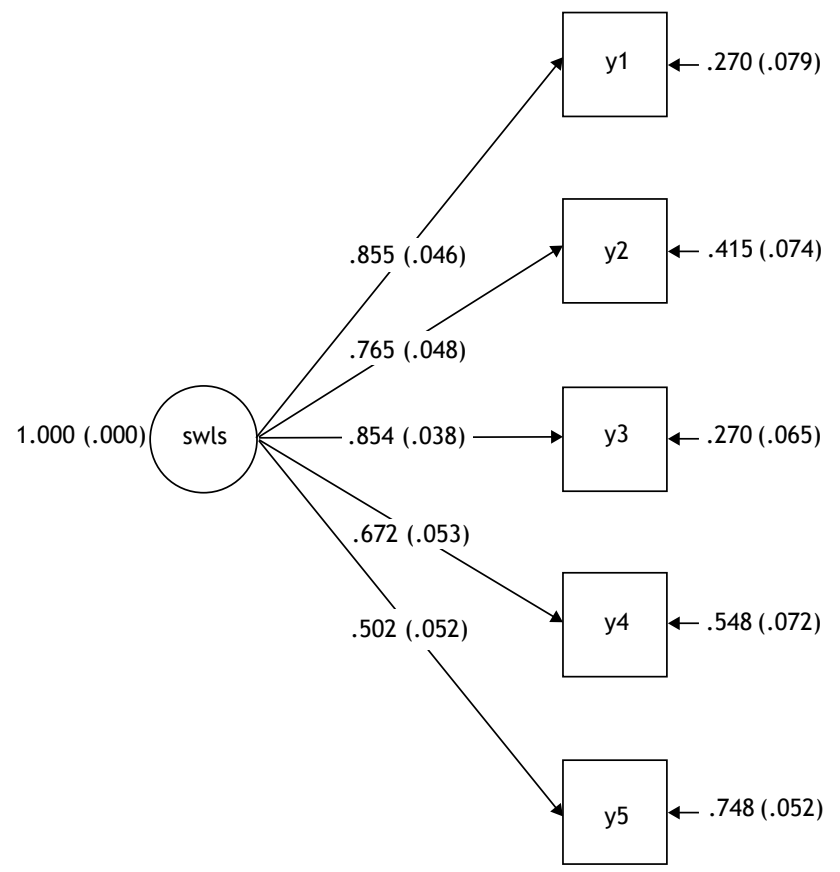

Figure 2. Path diagram of the Satisfaction with Life Scale for a sample of Spanish university students. 
Table 3 Factorial Invariance for the Satisfaction with Life Scale model according to gender in a sample of Chilean and Spanish university students

\begin{tabular}{lcccccccc}
\hline \multicolumn{1}{c}{ Model } & $\chi^{2}$ & df & D_SB $\chi^{2}$ & D_df & P_D_SB $\chi^{2}$ & RMSEA & CFI & TLI \\
\hline 0 Configural (without invariance) & 25.600 & 14 & - & - & - & 0.084 & 0.993 & 0.989 \\
1 Metric (all loadings fixed) & 23.134 & 20 & 5.803 & 5 & 0.326 & 0.046 & 0.997 & 0.997 \\
2 Scalar (all loadings and thresholds fixed) & 37.558 & 33 & 16.711 & 15 & 0.336 & 0.032 & 0.997 & 0.998 \\
\hline
\end{tabular}

$\chi^{2}=$ Chi square. $\mathrm{df}=$ Degrees of freedom. D_SB $\chi^{2}=$ Delta of Satorra-Bentler adjustment of Chi-square. D_df = Delta of degrees of freedom. P_D_SB $\chi^{2}=$ Statistical significance of Delta of Satorra-Bentler adjustment of Chi-square. RMSEA = Root Mean Square Error of Approximations. $\mathrm{CFI}=$ Comparative Fit Index. TLI = Tuker-Lewis Index.

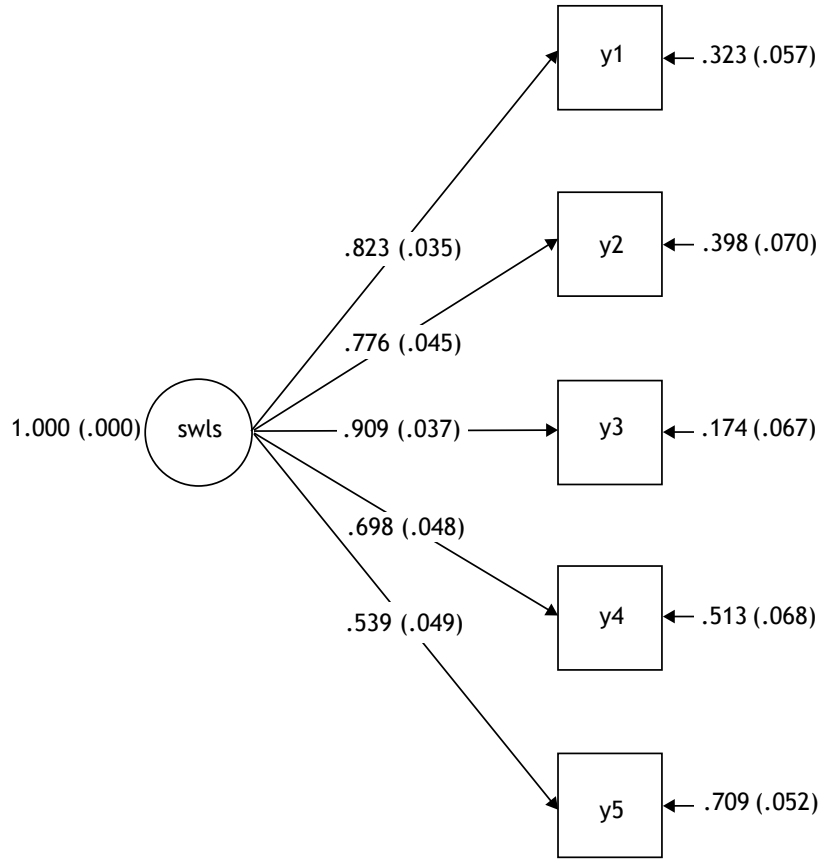

Figure 3. Path diagram of the Satisfaction with Life Scale for a sample of male university students from Chile and Spain.

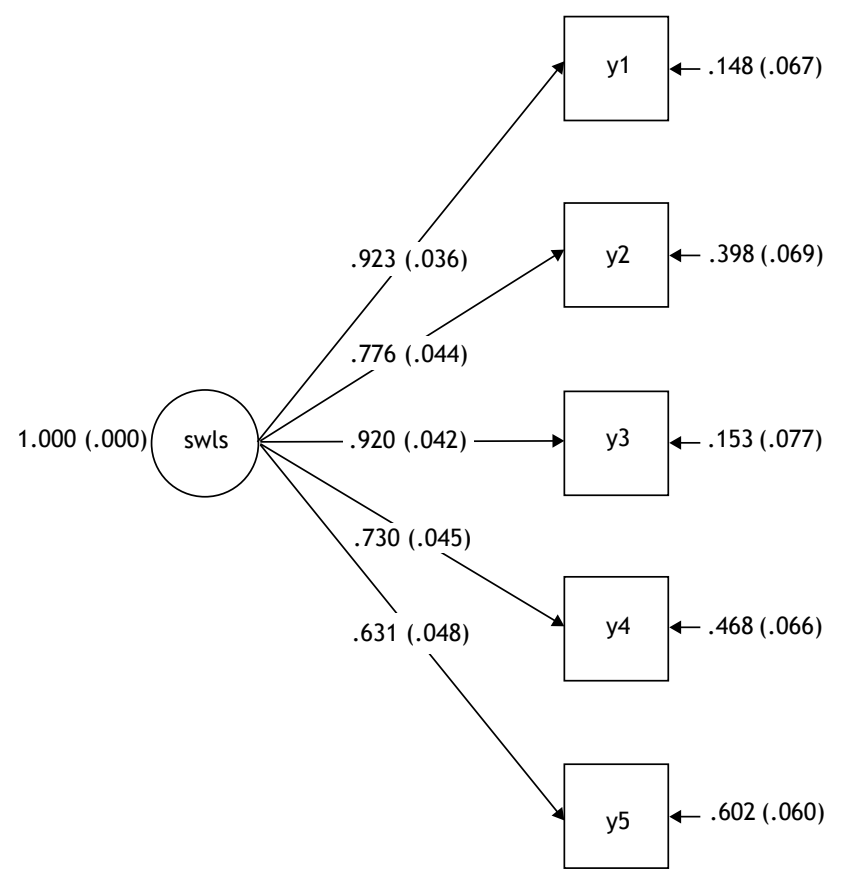

Figure 4. Path diagram of the Satisfaction with Life Scale for a sample of female university students from Chile and Spain.
These findings are consistent with results obtained by Tucker et al. (2006) when comparing US and Russian student samples, and also to those obtained by Ponizovsky et al. (2013) from immigrants from the Former Soviet Union in Israel, Bulgaria, and Germany. However, these results contradict those obtained by Dimitrova and Dominguez (2015) in adults from three Spanish-speaking countries in America (intercepts of items 2 and 3 non invariant), those by Atienza et al. (2016) in adolescents from Spain and Portugal (intercept for item 5 not invariant), and those by Whisman and Judd (2016) in middle-aged and elderly adults from the US, England, and Japan (intercept for item 4 not invariant). These studies reported only partial scalar invariance. Further research is necessary to explore the characteristics that account for scalar invariance levels in different groups (e.g., students, immigrants).

The findings from this study suggest a greater influence of common characteristics in Mediterranean and South American countries, than that of their cultural differences (Arenas-Gaitán et al., 2011). Among these commonalities are language and the cultural tendency of Chilean and Spanish young people to live with their parents for a longer period, often during their university studies (Crocetti \& Meeus, 2014; Schnettler et al., 2016). There are antecedents of full cross-cultural scalar invariance among groups with marked cultural differences and different languages, such as those reported by Tucker et al. (2006), and among immigrant groups in the same country (Ponizovsky et al., 2013). At the same time, only partial scalar invariance has been supported among samples of different ages who speak the same language (Dimitrova \& Dominguez, 2015; Schnettler et al., 2017) and share a similar culture (Atienza et al., 2016), as well as among countries with marked cultural disparities (Whisman \& Judd, 2016). Against this evidence, the present study shows that university populations from Chile and Spain share cultural conceptualisations regarding satisfaction with life.

SWLS items 4 and 5 did not differ between Chilean and Spanish participants. There are mixed findings regarding the cross-cultural discrepancies in these items, as they suggest a sense of accomplishment that younger participants might not be able to report. Some authors argue that item 4 might be positively linked with age and item 5 might be negatively linked with age (Atienza et al., 2016; Casas et al., 2012). Moreover, it has been suggested that items 4 and 5 are related to the past while the other three items focus on the present (Oishi, 2006; Whisman \& Judd, 2016). Further research should evaluate the cross-cultural measurement invariance of the SWLS both among countries with large cultural differences and different languages (e.g., Western and Eastern countries), as well as in countries with similar 
cultures. These studies should consider, for instance, samples from Mediterranean countries and countries in which emerging adults are expected to leave home in their early twenties, as is the case in the US and in Northern Europe (Crocetti \& Meeus, 2014). In addition, because the level of economic development differs among South American countries, as well as conditions of access and funding for higher education, future studies should consider university student samples from different South American countries to evaluate cross-cultural measurement invariance in the SWLS.

Lastly, measurement invariance across genders was also assessed regardless of the country of origin. The results also suggest configural, metric and scalar invariance of the SWLS in male and female university students from Chile and Spain. These findings agree with the results of previous studies in university student samples showing that this scale is invariant across genders (Hultell \& Gustavsson, 2008; Shevlin et al., 1998; Tomás et al., 2015). It should be highlighted, however, that our results indicate that the SWLS is invariant across genders even when participants are of a different nationality.

\section{Limitations}

The first limitation of this study is the non-probabilistic nature of the two samples, and their relatively small sizes. The Chilean sample only included students from five out of the 18 state universities in the country, and the Spanish sample only included one university. Moreover, the Chilean sample was representative of the national university student population in terms of age, but it has a higher proportion of female students than reported in the general student population (Consejo Nacional de Educación, 2014). For its part, the Spanish sample was representative of the undergraduate student population in Spain in terms of age and gender (Ministerio de Educación, Cultura y Deporte, $\mathrm{n} / \mathrm{d})$. Further studies should consider cross-cultural comparisons between these countries with representative university samples to support and generalise the findings reported here. A second limitation of this study was that data were self-reported. Hence, responses may have been affected by recall bias or social desirability.

\section{Conclusion}

Despite its limitations, this study provides evidence that the Satisfaction with Life Scale (SWLS) is interpreted correspondingly by university students in Chile and Spain alike, regardless of gender. SWLS measurement invariance has been widely tested across diverse cultural contexts and populations, but studies focusing on samples from adults in higher education have received less attention. The similar SWLS structure shown in university samples from two Spanish-speaking countries is an opportunity for significant latent mean comparisons in research, detecting variables that can influence life satisfaction and overall SWB. On a practical level, an instrument that measures life satisfaction consistently throughout student populations can inform the creation of common policies for improving the living conditions of university students both in developed and developing Spanish-speaking countries.

\section{Acknowledgements}

This work was supported by Fondecyt Project 1160005 and Project AGL2015-65897-C3-1 of the Ministry of Economics and Competitivity of the Government of Spain.

\section{References}

Arenas-Gaitán, J., Ramírez-Correa, P. E., \& Rondán-Cataluña, F. J. (2011). Cross cultural analysis of the use and perceptions of web-based learning systems. Computers \& Education, 57(2), 1762-1774. https://doi.org/10.1016/j.compedu.2011.03.016

Arita, B. (2005). Satisfacción por la vida y teoría homeostática del bienestar. Psicología y Salud, 15(1), 121-126.

Atienza, F., Balaguer, I., Corte-Real, N., \& Fonseca, A. (2016). Factorial invariance of the Satisfaction with Life Scale in adolescents from Spain and Portugal. Psicothema, 28(3), 353-358. https://doi.org/10.7334/psicothema2016.1

Cadime, I., Lima, S., Marques Pinto, A., \& Ribeiro, I. (2016). Measurement invariance of the Utrecht Work Engagement Scale for Students: A study across secondary school pupils and university students. European Journal of Developmental Psychology, 13(2), 254-263. https://doi.org/10.1080/17405629.2016.1148595

Casas, F., Sarriera, J. C., Abs, D., Coenders, G., Alfaro, J., Saforcada, E., \& Tonon, G. (2012). Subjective indicators of personal well-being among adolescents. Performance and results for different scales in Latin-language speaking countries: A contribution to the international debate. Child Indicators Research, 5(1), 1-28. https://doi.org/10.1007/s12187-011-9119-1

Çivitci, A. (2015). The moderating role of positive and negative affect on the relationship between perceived social support and stress in College Students. Educational Sciences: Theory and Practice, 15(3), 565-573. https://doi.org/10.12738/ estp.2015.3.2553

Clench-Aas, J., Nes, R. B., Dalgard, O. S., \& Aarø, L. E. (2011). Dimensionality and measurement invariance in the Satisfaction with Life Scale in Norway. Quality of Life Research, 20(8), 13071317. https://doi.org/10.1007/s11136-011-9859-x

Consejo Nacional de Educación [CNED] (2014). Estadísticas y bases de datos INDICES [base de datos en línea], Santiago de Chile.

Crocetti, E., \& Meeus, W. (2014). “Family comes first!” Relationships with family and friends in Italian emerging adults. Journal of Adolescence, 37, 1463-1473. https://doi.org/10.1016/j. adolescence.2014.02.012

Díaz, D., Stavraki, M., Blanco, A., \& Gandarillas, B. (2015). The eudaimonic component of satisfaction with life and psychological well-being in Spanish cultures. Psicothema, 27(3), 247-253. https://doi.org/10.7334/psicothema2015.5

Diener, E., \& Biswas-Diener, R. (2000). New directions in subjective well-being research: The cutting edge. Indian Journal of Clinical Psychology, 27(1), 21-33.

Diener, E., Emmons, R., Larsen, R., \& Griffin, S. (1985). The satisfaction with life scale. Journal of Personality Assessment, 49, 71-75. https://doi.org/10.1207/s15327752jpa4901_13

Diener, E., Inglehart, R., \& Tay, L. (2013). Theory and validity of life satisfaction scales. Social Indicators Research, 112(3), 497527. https://doi.org/10.1007/s11205-012-0076-y

Dimitrova, R., \& Dominguez, A. (2015). Measurement Invariance of the Satisfaction with Life Scale in Argentina, Mexico and Nicaragua. Social Inquiry into Well-being, 1, 32-39.

Dimitrov, D. M. (2010). Testing for factorial invariance in the context of construct validation. Measurement and Evaluation in Counseling and Development, 43(2), 121-149. https://doi. org/10.1177/0748175610373459 
Esnaola, I., Benito, M., Antonio-Agirre, I., Freeman, J., \& Sarasa, M. (2017). Measurement invariance of the Satisfaction With Life Scale (SWLS) by country, gender and age. Psicothema, 29(4), 596-601. https://doi.org/10.7334/psicothema2016.394

Hiçdurmaz, D., İnci, F., \& Karahan, S. (2017). Predictors of mental health symptoms, automatic thoughts, and self-esteem among university students. Psychological Reports, 120(4). https://doi. org $/ 10.1177 / 0033294117707945$

Hofstede, G., \& Bond, M. H. (1988). The Confucius connection: From cultural roots to economic growth. Organizational Dynamics, 16(4), 5-21. https://doi.org/10.1016/0090-2616(88)90009-5

Hu, L., \& Bentler, P. M. (1999). Cutoff criteria for fit indexes in covariance structure analysis: Conventional criteria versus new alternatives. Structural Equation Modeling, 6(1), 1-55. https:// doi.org/10.1080/10705519909540118

Huang, L., Malone, P., Lansford, J., Deater-Deckard, K., Di Giunta, L., Bombi, A., Bornstein, M., Chang, L., Dodge, K., Oburu, P., Pastorelli, C., Skinner, A., Sorbring, E., Tapanya, S., Uribe, L., Zelli, A., Alampay, L., Al-Hassan, S., \& Bacchini, D. (2011). Measurement invariance of discipline in different cultural contexts. Family Science, 2(3), 212-219. https://doi.org/10.1080/19 424620.2011 .655997

Hultell, D., \& Gustavsson, J. P. (2008). A psychometric evaluation of the Satisfaction with Life Scale in a Swedish nationwide sample of university students. Personality and Individual Differences, 44(5), 1070-1079. https://doi.org/10.1016/j.paid.2007.10.030

Jang, S., Kim, E., Cao, C., Allen, T., Cooper, C., Lapierre, L., O’Driscoll, P., Sanchez, J., Spector, P., Poelmans, P., Abarca, A., Alexandrova, M., Antoniou, A., Beham, B., Brough, P., Carikci, I., Ferreiro, P., Fraile, G., Geurts, S.,...Woo, J-M. (2017). Measurement invariance of the Satisfaction With Life Scale across 26 countries. Journal of Cross-Cultural Psychology, 1-17. https://doi.org/10.1177/0022022117697844

MacCallum, R. C., Browne, M. W., \& Cai, L. (2006). Testing differences between nested covariance structure models: Power analysis and null hypotheses. Psychological Methods, 11(1), 19. https://doi.org/10.1037/1082-989X.11.1.19

Marsh, H. W., Hau, K.-T., \& Wen, Z. (2004). In search of golden rules: Comment on hypothesis-testing approaches to setting cutoff values for fit indexes and dangers in overgeneralizing Hu and Bentler's (1999) findings. Structural Equation Modeling, 11, 320-341. https://doi.org/10.1207/s15328007sem1103_2

Ministerio de Educación, Cultura y Deporte (n/d). Datos y Cifras del Sistema universitario español Curso 2014-2015. https://sede. educacion.gob.es/publiventa/d/20382/19/1

Lee, K., Kang, S., \& Kim, I. (2017). Relationships among stress, burnout, athletic identity, and athlete satisfaction in students at Korea's physical education high schools: Validating differences between pathways according to ego resilience. Psychological Reports, 120(4). https://doi.org/10.1177/0033294117698465

Oishi, S. (2006). The concept of life satisfaction across cultures: An IRT analysis. Journal of Research in Personality, 40(4), 411-423. https://doi.org/10.1016/j.jrp.2005.02.002

Ponizovsky, Y., Dimitrova, R., Schachner, M. K., \& Van de Schoot, R. (2013). The Satisfaction With Life Scale: Measurement invariance across immigrant groups. European Journal of Developmental Psychology, 10(4), 526-532. https://doi.org/10.1080/17 405629.2012.707778

Putnick, D. L., \& Bornstein, M. H. (2016). Measurement invariance conventions and reporting: The state of the art and future directions for psychological research. Developmental Review, 41, 71-90. https://doi.org/10.1016/j.dr.2016.06.004

Salazar-Fernández, C., Navarro, R. M., Schnettler, B., \& Saiz, J. L. (2020). Life satisfaction among indigenous people from Chile: Evaluation of measurement invariance. Revista Latinoamericana de Psicología, 52, 33-41. https://doi.org/10.14349/rlp.2020.v52.4
Satorra, A., \& Bentler, P. M. (2001). A scaled difference chi-square test statistic for moment structure analysis. Psychometrika, 66, 507-514. https://doi.org/10.1007/BF02296192

Schnettler, B., Miranda, H., Sepúlveda, J., Denegri, M., Mora, M., Lobos, G., \& Grunert, K. G. (2013). Psychometric properties of the Satisfaction with Food-Related Life Scale: Application in southern Chile. Journal of Nutrition Education and Behavior, 45(5), 443-449. https://doi.org/10.1016/j.jneb.2012.08.003

Schnettler, B., Denegri, M., Miranda, H., Sepúlveda, J., Mora, M., \& Lobos, G. (2014). Satisfaction with life and with food-related life in central Chile. Psicothema, 26(2), 200-206. https://doi. org/10.7334/psicothema2013.13

Schnettler, B., Lobos, G., Orellana, L., Grunert, K., Sepúlveda, J., Mora, M., Denegri, M., \& Miranda, H. (2015). Analyzing food-related life satisfaction and other predictors of life satisfaction in central Chile. The Spanish Journal of Psychology, 18, E38. https://doi.org/10.1017/sjp.2015.32

Schnettler, B., Höger, Y., Orellana, L., Sepúlveda, J., Salinas-Oñate, N., Lobos, G., \& Grunert, K. G. (2016). Family eating habits, family support and subjective well-being in university students in Chile. Nutrición Hospitalaria, 33(2), 451-458.

Schnettler, B., Miranda-Zapata, E., Lobos, G., Lapo, M.C., Adasme-Berríos, C., \& Hueche, C. (2017). Measurement invariance in the Satisfaction with Life Scale in Chilean and Ecuadorian older adults. Personality and Individual Differences, 110, 96101. https://doi.org/10.1016/j.paid.2017.01.036

Shevlin, M., Brunsden, V., \& Miles, J. N. V. (1998). Satisfaction with life scale: Analysis of factorial invariance, mean structures and reliability. Personality and Individual Differences, 25(5), 911916. https://doi.org/10.1016/S0191-8869(98)00088-9

Sovet, L., Atitsogbe, K. A., Pari, P., Park, M. S. A., \& Villieux, A. (2016). Psychometric evaluation of the satisfaction with life scale in Togo: A three-step approach. Revue Européenne de Psychologie Appliquée/European Review of Applied Psychology, 66(5), 243-250. https://doi.org/10.1016/j.erap.2016.06.002

Swami, V., \& Chamorro-Premuzic, T. (2009). Psychometric evaluation of the Malay Satisfaction With Life Scale. Social Indicators Research, 92, 25-33. https://doi.org/10.1007/s11205-008-9295-7

Tomás, J. M., Gutiérrez, M., Sancho, P., \& Romero, I. (2015). Measurement invariance of the Satisfaction With Life Scale (SWLS) by gender and age in Angola. Personality and Individual Differences, 85, 182-186. https://doi.org/10.1016/j.paid.2015.05.008

Tsitsas, G., Nanopoulos, P., \& Paschali, A. (2019). Life satisfaction, and anxiety levels among university students. Creative Education, 10, 947-961. https://doi.org/10.4236/ce.2019.105071

Tucker, K. L., Ozer, D. J., Lyubomirsky, S., \& Boehm, J. K. (2006). Testing for measurement invariance in the satisfaction with life scale: A comparison of Russians and North Americans. Social Indicators Research, 78(2), 341-360. https://doi.org/10.1007/ s11205-005-1037-5

Vázquez, C., Duque, A., \& Hervás, G. (2013). Satisfaction with life scale in a representative sample of Spanish adults: Validation and normative data. The Spanish Journal of Psychology, 16(82), 1-15. https://doi.org/10.1017/sjp.2013.82

Whisman, M. A., \& Judd, C. M. (2016). A cross-national analysis of measurement invariance of the Satisfaction With Life Scale. Psychological Assessment, 28(2), 239-244. https://doi.org/ 10.1037/pas0000181

Wu, C.H., Chen, L.H., \& Tsai, Y.M. (2009). Longitudinal invariance analysis of the satisfaction with life scale. Personality and Individual Differences, 46(4), 396-401. https://doi.org/10.1016/j. paid.2008.11.002

Zanon, C., Bardagi, M. P., Layous, K., \& Hutz, C. (2014). Validation of the Satisfaction with Life Scale to Brazilians: Evidences of measurement noninvariance across Brazil and US. Social Indicators Research, 119, 443-453. https://doi.org/10.1007/ s11205-013-0478-5 